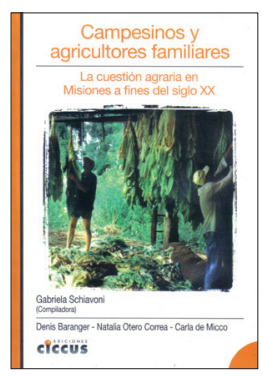

\title{
Gabriela Schiavoni (comp.). Campesinos y agricultores familiares. La cuestión agraria en Misiones a fines del siglo XX
}

\author{
Buenos Aires: Ediciones Ciccus, 2008. 184 p.
}

\author{
Roxana Lorena Kasiañuk ${ }^{1}$
}

Esta obra aborda el conflicto por la tierra y el desarrollo rural de la pequeña agricultura en el capitalismo tardío; analizándolo en la última década del siglo XX en la frontera agraria del nordeste de Misiones. El tema en cuestión se refiere a la expansión de la frontera agrícola, Ilevada a cabo mediante procesos de ocupación espontánea por pequeños productores vinculados precariamente a la tierra.

Este libro surge de un trabajo colectivo titulado "El campo del desarrollo rural y los conflictos por la tierra en la frontera agraria de Misiones", creado por doctores y docentes en Sociología de la Universidad Nacional de Misiones.

La obra se organiza en siete capítulos, indagando cada uno en las condiciones de desarrollo de la agricultura familiar en Misiones. En el primero, Repensar la reproducción Del campesinado a la agricultura familiar, Gabriela Schiavoni analiza la problemática de la reproducción social de los pequeños productores en los contextos débilmente institucionalizados del capitalismo actual, a través de letrados en sociología, como Marx, Bourdieu y Max Weber, entre otros. En este sentido la autora expresa que estas unidades (el campesinado) evolucionan hacia la categoría de agricultores profesionalizados, tecnificados, proletarios disfrazados, entre otros.

En el segundo capítulo, La construcción del campesinado en Misiones: de las Ligas Agrarias a los sin tierra, Denis Baranger describe la situación de Argentina a partir de la

1 Estudiante de Profesorado y Licenciatura en Geografía, Universidad Nacional de Tucumán (Argentina). E-mail: roxanalkgeo@hotmail.com década del 70, relatando la forma en que la provincia de Misiones se puebla de inmigrantes europeos a lo largo del siglo XX, dedicándose a distintos cultivos industriales, como el tabaco y la yerba mate. Enfatiza además que en la década mencionada se inició una crisis de la agricultura familiar, lo que dio como resultado el descenso en los precios de los cultivos industriales, teniendo como consecuencia la formación del MAM (Movimiento Agrario de Misiones). En 1987 el MAM empezó a luchar por la tierra y así en 1994 se constituye el MSTM (Movimiento de los Sin Tierra en Misiones) apoyados por el MST brasileño, la FAA (Federación Agraria Argentina) y por la Iglesia Católica. El autor hace una breve pero interesante diferenciación entre el MST brasileño, que se manifiesta en todo su país con invasiones masivas y sorpresivas, y el MSTM, que data de su ubicación puntual y cuyas ocupaciones son espontáneas y se realizan de modo paulatino y silencioso.

Natalia Otero, en el capítulo De la chacra al corte. Los dirigentes de Unión Campesina y la lucha por la tierra en el nordeste de Misiones, indaga en el deseo de no ser desalojados de estos pequeños productores al invadir tierras fiscales y privadas desde hace más de veinte años (en algunos casos), frente al deseo de los propietarios, quienes querían expulsarlos para poder vender sus tierras; ante estas amenazas algunos optaron por marcharse y otros, por quedarse y luchar. Dada la situación, estos pequeños productores eran llamados por los medios de comunicación como intrusos o usurpadores, y desde el año 2000 han realizado diferentes acciones para obtener la propiedad de la tierra y mejorar la infraestructura, por medio de la adquisición de alumbrado público, agua potable, servicios de cloacas, entre otros. De esta 
manera, en el año 2004 se conforma una organización de pequeños productores Ilamada Unión Campesina (UC), que significa unión de toda el área de campo. La UC en apoyo de APHYDAL (Asociación para la promoción humana y el desarrollo agroecológico local) pueden acceder a programas de desarrollo como Manos a la Obra y Programa Social Agropecuario, con lo que se abren grandes posibilidades de aumentar la calidad de vida de las familias convivientes de dichas tierras.

En el cuarto capítulo, Nuevas organizaciones agrarias. Plantadores y campesinos en el nordeste de Misiones, Gabriela Schiavoni plantea el desempeño de los campesinos en las plantaciones de tabaco Burley, organizados por la APTM (Asociación de Plantadores de Tabaco de Misiones). Dicha corporación tiene por objetivos defender al productor tabacalero, buscar armonía con el estado provincial y nacional, defender la unión de todos los agricultores tabacaleros de la provincia, optimizar el precio real del tabaco, entre otros. El unirse a esta organización encuentra su respuesta esencialmente en que estos productores necesitan de organizaciones que los amparen, ya que en los últimos años son mayores las exigencias para poder comercializar el tabaco, principalmente la limpieza y prolijidad, como también galpones cerrados de uso exclusivo para dicho producto.

Un quinto capítulo, se refiere a las Agencias y núcleos de desarrollo en el nordeste misionero, donde Carla de Mico muestra el debate de los Ilamados "técnicos" o "agentes de cambio", que son quienes interactúan con los pequeños productores de los programas estatales de desarrollo rural para buscar mejoras en la calidad de vida de los productores mediante la incorporación de tecnología adecuada para aumentar la productividad, coordinar la lucha por la tierra, etc. Debido a la mencionada actividad, estos técnicos también son Ilamados "núcleos de desarrollo".

En el sexto capítulo, Madereros y agricultores. La constitución de un mercado de tierras en el nordeste de Misiones, Gabriela Schiavoni hace referencia a la extracción de madera de forma indiscriminada, haciendo desaparecer el monte nativo, perdiendo así gran parte del valor original; por lo tanto, la dificultad de reforestar dichas tierras (14 años) para obtener ganancias que representan aproximadamente el $10 \%$ de la remuneración otorgada por la plantación de tabaco en un año, los hace desistir del uso de tierras foresto-industriales. La autora además indica que en el acceso a la tierra intervienen tanto madereros como agricultores, siendo los primeros los propietarios y los segundos los ocupantes.

La misma investigadora en el apartado Notas sobre el brique o negocio amistoso, menciona que el brique es una forma de trueque, entendido como parte de transacciones informales que se llevan a cabo entre familiares, amigos y conocidos que involucra tierra, animales, vehículos, electrodomésticos, entre otros. El briquero es quien realiza el trueque buscando siempre buenas ocasiones de intercambio. En general entre los campesinos estos personajes no tienen buena aceptación, pero aducen que en ocasiones son muy necesarios, por ejemplo, si un campesino necesita dinero para una internación, realiza un trueque cambiando una camioneta por dinero.

Como análisis final se puede expresar que la virtuosidad de los autores se ve reflejada al comienzo del libro dado que explica al lector que durante la lectura del mismo, se encontrará con frases repetidas en las distintas contribuciones, analizados por distintos observadores y desde diferentes puntos de vista según el estudio de casos.

Este trabajo se acompaña de un mapa de la provincia de Misiones, tablas, cuadros y el glosario de siglas, quedando ensamblados de manera muy inteligible; también subrayo el diseño de la portada ya que la fotografía refleja perfectamente lo expresado en el libro.

Otras de las virtudes que resaltan en este texto, es cómo los autores expresan los testimonios de los campesinos, lo que provocaría en el lector cierta empatía debido a los inconvenientes que poseen estas personas para obtener el derecho a las tierras.

Finalmente, cabe mencionar la claridad de expresión e información de este libro, considerándolo muy aconsejable y novedoso para aquellos que quieran conocer de cerca la problemática territorial de campesinos y agricultores familiares del nordeste de Misiones. 